\title{
Peyronie's disease in a district general hospital
}

\author{
VICTOR O. N. ODIASE \\ F.R.C.S.(Ed), F.R.C.S.(Eng)
}

\author{
ROBERT H. WHITAKER \\ M.Chir., F.R.C.S.
}

\author{
Department of Urology, Addenbrooke's Hospital, Cambridge
}

\begin{abstract}
Summary
Peyronie's disease can cause severe physical and psychological distress. Of 31 cases in this retrospective study, 12 underwent spontaneous improvement in their symptoms which makes the assessment of active treatment in other patients difficult. The indications and limitations of operative approach are discussed.
\end{abstract}

\section{Introduction}

The 17th century French periodical 'Les Ephémèrides des Animaux de la Nature' is alleged to have mentioned the condition which is now recognized as Peyronie's disease (Merle, 1899; Fogh-Anderson, 1957; Chesney, 1975). However, it was not until François de la Peyronie (1743) published his article on 'some obstacles opposing the natural ejaculation of semen' that the clinical entity gained recognition and became known by his name. He described 3 patients who had pain and associated curvature of the penis on erection and were found on examination to have thickened fibrous areas in the shaft of the penis. The work of Smith (1966) has resulted in the recognition of an early phase of the disease characterized by aggregation of lymphocytes and plasma cells around the vessels in the connective tissue between the tunica albuginea and corpora cavernosa and a later phase when these chronic inflammatory changes are replaced by a fibrous plaque. There are very few lymphocytes or plasma cells seen in the later phase and the fibrous plaque may become ossified. The aetiology and satisfactory management of this disease remain contentious. Thirty-one cases seen in the clinic of one of the authors over a 5-year period are retrospectively studied.

\section{Patients and methods}

\section{Diagnosis and investigations}

Thirty-one patients referred by their general practitioners were diagnosed as suffering from Peyronie's disease. There were 5 main symptoms of which the patients complained and these were

(1) deformity of the penis on erection;
(2) lump in the penis;

(3) pain in the penis on erection;

(4) difficulty in performing sexual intercourse;

(5) proximal distension and distal laxity of the erect penis.

The past illnesses which could be significant and any factors which might have a predisposing influence were recorded. The diagnosis was confirmed by feeling the typical fibrous plaque. The authors found that the plaque was easiest to feel with the fingers on the 2 lateral sides of the penis and indeed may not be detectable in the antero-posterior plane. An X-ray of the penis was taken in one of the severe cases; histological examination was available in the 3 patients who underwent operation.

\section{Management}

All patients were reassured that the illness from which they suffered was not malignant and that there was a tendency for the condition to improve spontaneously. The more severe cases, and those who insisted on treatment even though their disease was mild, were treated with potassium para-aminobenzoate (Zarafonetis and Horrax, 1959). Three patients have had an operation and 2 more are awaiting it. The criteria for surgery were a very large fibrous plaque producing severe deformity and a plaque which, though not necessarily large, resulted in laxity of the distal part of the erect penis. Numerous types of operation have been described for Peyronie's disease but the authors preferred the technique of Devine and Horton (1974) of excising the plaque of fibrous tissue and repairing the tunica albuginea with a free dermal graft. The only modification made was to obtain the skin graft from the anterior aspect of the thigh rather than the abdominal wall. The skin, as Devine and Horton suggested, was denuded of its epidermis and underlying fat.

\section{Results}

The ages of the thirty-one patients with Peyronie's disease ranged from 20 to 72 years and the age 
distribution is illustrated in Fig. 1. In this retrospective study only 24 patients timed the onset of symptoms precisely (Fig. 2). The patients' complaints are summarized in Table 1. The past illnesses which could be significant were recorded: mumps, one case; ankylosing spondylitis, one case; osteoarthritis, 2 cases; severe disc lesion, 2 cases; urinary tract infection, 2 cases; prostatism, 2 cases; trauma, 2 cases.

One of the patients timed the onset of his disease with an episode of trauma during forceful sexual intercourse while another patient related it to the time his wife began using a ring pessary to correct a retroverted uterus. The only penis that was X-rayed, a severe case, revealed calcification of the plaque. Histological examination of the plaques removed from the 3 patients treated surgically showed thick fibrous tissue between the tunica albuginea and corpora cavernosa with minimal cellular reaction.

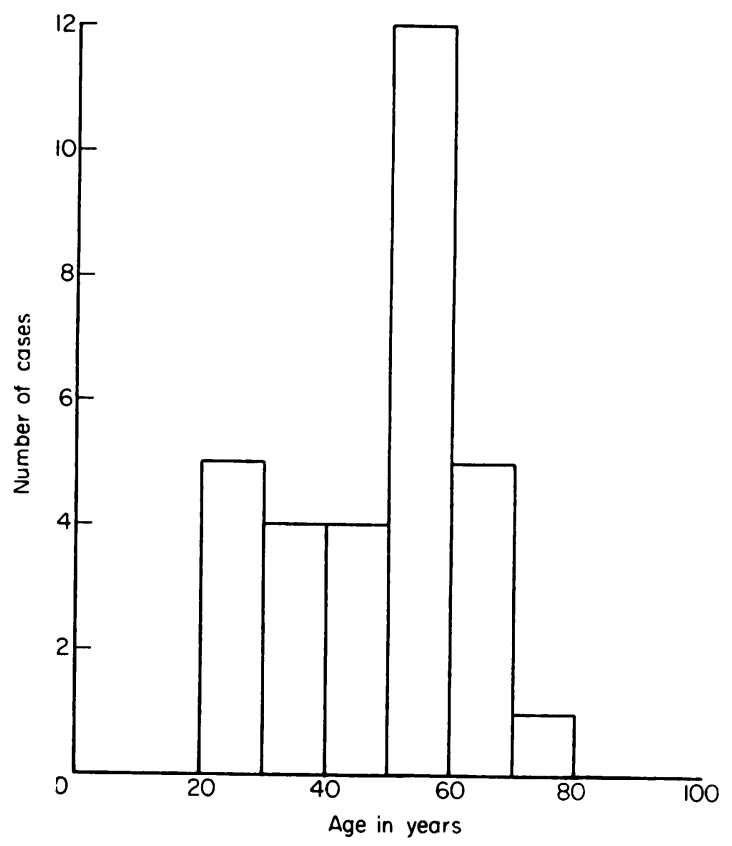

FIG. 1 Age distribution of patients with Peyronie's disease.

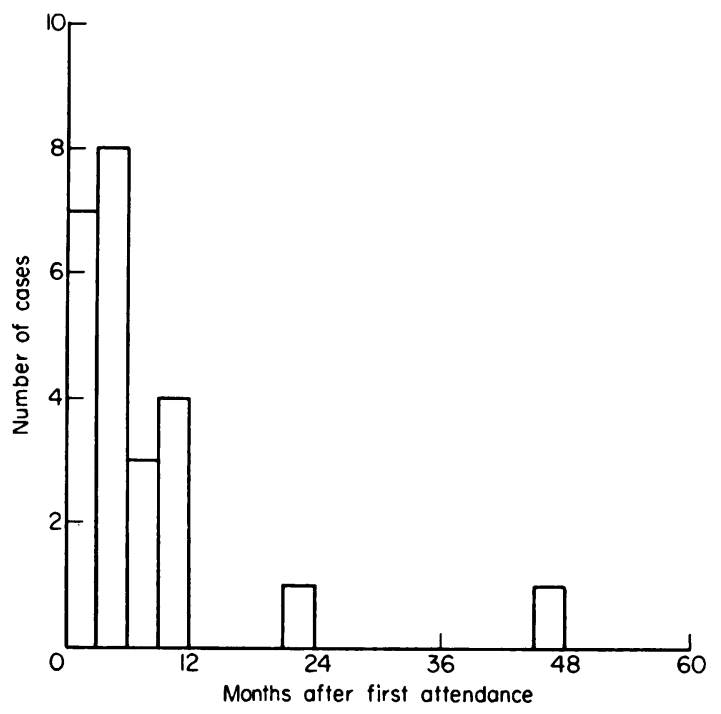

Fig 2. Duration of symptoms at first attendance.

The results of the management were categorized as 'Improved', 'Worse' and 'No change' (Table 2). The classification was based on a consideration of the patients' symptoms and physical findings at follow-up attendances. The patients who improvedo accepted that pain was less and sexual intercourse. had improved but rarely admitted improvement in the deformity of the penis. Complications from the treatment are noted in Table 2.

\section{Discussion}

Peyronie's disease is a disease of middle age as shown in Fig. 1 with an average age of onset of 47 years in this series. Others have found a similar age incidence of 49 years (Morales and Bruce, 1975) and 48 years (Raz, Dekernion and Kaufman, 1977). The disease does not appear to cause acute symptoms in many patients and this results in an average delay of 8 months before consultation. This is similar to the average of 9 months in the series of Winter and Khanna (1975). While deformity of the penis was the most common complaint $(80 \%)$ in this series, proximal distension and distal

TABLE 1. Complaints of patients

\begin{tabular}{lccccc}
\hline & $\begin{array}{c}\text { Deformity of penis } \\
\text { on erection }\end{array}$ & $\begin{array}{c}\text { Difficulty with } \\
\text { sexual intercourse }\end{array}$ & $\begin{array}{c}\text { Pain in penis } \\
\text { on erection }\end{array}$ & $\begin{array}{c}\text { Lump in penis } \\
\text { Proximal distension } \\
\text { and distal flaccidity } \\
\text { of penis }\end{array}$ \\
\hline $\begin{array}{l}\text { Number complaining } \\
\text { of symptom out of } \\
31(\%)\end{array}$ & $25(80)$ & $16(51)$ & $14(45)$ & $7(22)$ & $3(10)$ \\
\hline
\end{tabular}


TABLE 2. Summary of management

\begin{tabular}{|c|c|c|c|}
\hline Treatment & Number & $\begin{array}{l}\text { Outcome of } \\
\text { treatment }\end{array}$ & Complication of treatment \\
\hline No active treatment & 19 & $\begin{array}{l}\text { Improved (12) } \\
\text { No change (3) } \\
\text { Worse (4) }\end{array}$ & \\
\hline Potassium para-amino benzoate & 8 & $\begin{array}{l}\text { Improved (5) } \\
\text { No change (2) } \\
\text { Worse (1) }\end{array}$ & $\begin{array}{l}\text { (1) One patient developed gout every time he } \\
\text { took the drug } \\
\text { (2) One patient developed severe rash } \\
\text { following the drug }\end{array}$ \\
\hline Surgery & 3 & $\begin{array}{l}\text { Improved (2) } \\
\text { No change (1) } \\
\text { Worse }(0)\end{array}$ & $\begin{array}{l}\text { The penile skin of one patient sloughed. } \\
\text { Scrotal skin graft applied }\end{array}$ \\
\hline $\begin{array}{l}\text { Awaiting surgery (one transferred from the } \\
\text { para-amino benzoate group) }\end{array}$ & 2 & No change & \\
\hline
\end{tabular}

laxity of the erect penis $(10 \%)$ formed one of the major indications for offering surgery to the patient. The authors felt that the fibrous plaque was causing a constriction of the corpora cavernosa and this was best dealt with by excision.

The aetiology of Peyronie's disease remains obscure. It has been found to occur in association with urethritis (Smith, 1969), Dupuytren's contracture (Morales and Bruce, 1975; Chesney, 1975) and osteoarthritis (Furlow, Swenson and Lee, 1975). Although trauma has been suggested, the plasma and lymphocyte infiltration found around the vessels in the early stage of the disease has led to the speculation that it is more likely to be an auto-immune disease. In this series, 2 patients have firmly related the onset of their symptoms with trauma. In others arthritis and urinary infection have also been detected. The authors are, however, unable to attach any aetiological significance to them.

A satisfactory management of Peyronie's disease remains as elusive as its aetiology. Numerous forms of treatment have been suggested and each has had success claimed for it. As the untreated disease has a tendency to improve over approximately 4 years (Williams and Thomas, 1970) it is difficult to judge the efficacy of any form of treatment. This series has clearly shown that most of the untreated patients can improve spontaneously (Table 2). It should however be remembered that the patients in this group were those whose disease was considered mild. The severer forms of the disease automatically qualified the patients for treatment. A few patients whose disease was mild but who insisted on treatment were also treated. Potassium para-aminobenzoate produced improvement in $>60 \%$ in the group who had the drug although 2 patients $(25 \%)$ suffered severe drug reaction. Two of the 3 patients who have had surgery have recovered straight and stronger erection of the penis. One of these cases had a protracted recovery as the skin of the penis sloughed and needed a scrotal skin graft. The third patient was not improved by surgery.

No hard and fast rule can be formulated for the management of Peyronie's disease. Each case has to be assessed on its merit and when non-operative treatment is decided upon potassium para-aminobenzoate may offer some help. Surgery should not be undertaken lightly but, when indicated, excision of the fibrous plaque and free patch skin graft can restore the anatomy of the corpora cavernosa to produce an acceptably good result. Alternatively the deformity can be corrected by excising one or more pieces from the tunica albuginea opposite to the deformity (Pryor and Fitzpatrick, 1979). Surgery is probably best reserved for those who find sexual intercourse impossible and whose degree of deformity has become stable.

\section{References}

Chesney, J. (1975) Peyronie's disease. British Journal of Urology, 49, 209.

Devine Jr, C.J. \& HoRTon, C.E. (1974) Surgical treatment of Peyronie's disease with a dermal graft. Journal of Urology, $111,44$.

Fogh-ANDERSON, P. (1957) Treatment of plastic induration of the penis (Peyronie's disease). Acta chirugica scandinavica, 113, 45 .

Furlow, W., Swenson, H.E. \& Lee, R.E. (1975). Peyronie's disease: study of its natural history and treatment with orthovoltage radiotherapy. Journal of Urology, 114, 69.

Merle, N.M. (1899) Contribution à l'étude des corps caverneux et des os penis. Thèse de Toulouse.

Morales, A. \& Bruce, A.W. (1975) Treatment of Peyronie's disease with parathyroid hormone. Journal of Urology, 114, 901.

Peyronie, F. DE LA (1743) Sur quelques obstacles qui s'opposent à l'éjaculation naturelle de la semence. Mémoires de l'Académie de chirurgie, p. 425.

PryoR, J.P. \& FitzPATRICK, J.M. (1979) A new approach to 
the correction of the penile deformity in Peyronie's disease. Journal of Urology, 122, 622.

Raz, S., Dekernion, J.B. \& Kaufman, J. (1977) Surgical treatment of Peyronie's disease: new approach. Journal of Urology, 117, 598.

SMITH, B.H. (1966) Peyronie's disease. American Journal of Clinical Pathology, 45, 670.

Sмiтh, B.H. (1969) Subclinical Peyronie's disease. American Journal of Clinical Pathology, 52, 385.
Williams, J.L. \& Thomas, G.G. (1970) The natural history of Peyronie's disease. Journal of Urology, 103, 75.

Winter, C.C. \& Khanna, R. (1975) Peyronie's diseaseresults with dermojet injection of dexamethasone. Journal of Urolog. 114, 898.

Zarafonetis, C.J.D. \& HorRaX, T.M. (1959) Treatment of Peyronie's disease with potassium para-aminobenzoate (Potaba). Journal of Urology, 81, 779. 